\title{
СОВЕРШЕНСТВОВАНИЕ ПОДДЕРЖКИ И ЭКСПОРТНОЙ ЭКСПАНСИИ АГРОПРОМЫШЛЕННОГО КОМПЛЕКСА РОССИИ
}

\author{
E.V. Semenova, A.V. Pavlova

\begin{abstract}
THE IMPROVEMENT OF THE SUPPORT AND EXPORT EXPANSION OF AGRICULTURAL AND INDUSTRIAL COMPLEX OF RUSSIA
\end{abstract}

Рассматриваются вопросы развития поддержки аграрного комплекса России в контексте санкционного давления, трансформации конъюнктуры главных экспортных товаров, экономической стагнациии. В последние годы наблюдается изменение объемов господдержки сельхозпредприятий, их высокая дифференциация в разрезе федеральных округов, миграция программ консолидированного бюджетного финансирования предприятий АПК, появление новых ориентиров в государственной политике по направлению импортозамещения и развития агропродовольственного экспорта. Делаются выводы о противоречиях и разнонаправленных тенденциях государственного содействия сельскохозяйственным товаропроизводителям. Это определяет актуальность ревизии инструментов господдержки, условий и порядка ее осуществления, потребности ее совершенствования, а также формирования благоприятного климата экспортной экспансии агропромышленного комплекса России. Для повышения эффективности поддержки аграрного комплекса Российской Федераџии предлагается использование дифференцированных целевых ориентиров и индикаторов для субсидирования сельхозпредприятий; разделение федеральных целевых программ, подпрограмм, приоритетных проектов с учетом эндемических, природно-климатических характеристик территории и стратегчческих кластеров развития; отказ от таможенных ограничений на ввоз оборудования для пищевой и перерабатывающей промышленности; введение норм гуманитарной помощи и государственных гарантий иностранным государствам на закупку исключительно переработанной российской сельскохозяйственной продукции; оценка деятельности надзорных органов, торгпредств и других организаций по критерию расширения рынков сбыта российского агропродовольствия. Активизация традиционных инструментов аграрной государственной политики поддержки российского сельского хозяйства, а также применения новейших способов протекции отечественных сельскохозяйственных товаропроизводителей будет способствовать увеличению объема экспорта российской продукции агропромышленного комплекса и эффективности развития отрасли в целом. 


\section{Социально-экономический и әуманитарный журнал Красноярского ГАУ. 2020. №1}

Ключевъе слова: сельское хозяйство, продукция, государственная помощъ, санкции, экспорт, агропродовольственный рынок.

The matters of the development of support of agrarian complex of Russia in the context of sanctions pressure, the transformation of the environment of the main export goods, economic stagnation are considered. Lately the change of volumes of state support of agricultural enterprises, their high differentiation in the section of federal districts, migration of programs of consolidated budgetary financing of agrarian and industrial complexes enterprises, the emergence of new reference points in the state policy in the direction of import substitution and the development of agricultural production export has been observed. The conclusions about the contradictions and multidirectional tendencies of the state assistance to agricultural producers are drawn. It defines relevance of audit of instruments of the state support, conditions and an order of its implementation, the requirement of its improvement, and also the formation of favorable climate of export expansion of agrarian and industrial complex of Russia. For increasing the efficiency of the support of agrarian complex of the Russian Federation using differentiated target reference points and indicators for subsidizing of agricultural enterprises is offered; the division of federal target programs, subprogrammes, priority projects taking into account endemichesky, climatic characteristics of the territory and strategic clusters of development; refusal of customs restrictions on import of the equipment for food and processing industry; introduction of norms of humanitarian aid and the state guarantees to the foreign states on purchase of exclusively processed Russian agricultural production; the assessment of activity of supervisory authorities, trade missions and other organizations for criterion of expansion of sales markets of the Russian agricultural production. The activization of traditional tools of agrarian state policy of support of the Russian agriculture, and also application of the latest ways of the patronage of domestic agricultural producers will promote the increase in the volume of export of the Russian production of agrarian and industrial complex and the efficiency of the development of the branch in general.

Keywords: agriculture, production, state aid, sanctions, export, agricultural market.

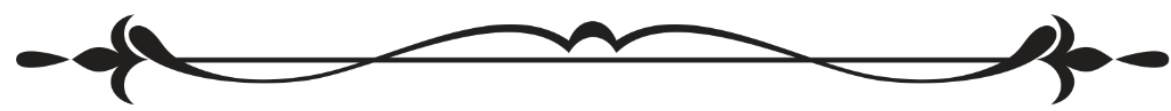

Введение. Современная аграрная политика направлена на повышение доходов граждан, занятых в агропромышленном комплексе, улучшение качества жизни в деревне, обеспечение продовольственной безопасности России. Для реализации обозначенных целей применяют- 
ся разные инструменты, в том числе стабильная, гибкая и системная государственная поддержка.

В последние годы наблюдается тенденция изменения объемов, направления и индикаторов привязки величины госфинансирования АПК РФ.

Цель исследования: определение основных тенденций развития государственной поддержки агропромышленного комплекса России, выявление ее проблемных моментов и определение основных направлений ее совершенствования.

Задачи исследования: проанализировать объемы и направления государственной поддержки АПК во временном и территориальном разрезе, а также определить направления совершенствования программ и подпрограмм федерального и регионального финансирования АПК.

Анализ объемов федерального и регионального финансирования АПК по 4 программам и 12 подпрограммам (без федерального проекта «Экспорт продукции агропромышленного комплекса») показал их снижение за пять лет. Объем консолидированной господдержки к 2019 г. составил всего 63 \% от объема помощи в 2015 г. (табл. 1).

Таблица 1

\section{Объемы финансирования государственной поддержки} АПК РФ [3]

\begin{tabular}{|l|c|c|c|}
\hline \multirow{2}{*}{ Год } & \multicolumn{3}{|c|}{ Предусмотрено всего, тыс. руб. } \\
\cline { 3 - 4 } & \multirow{2}{*}{ Всего } & \multicolumn{2}{|c|}{ В т. ч. за счет средств } \\
\cline { 3 - 4 } & & федерального бюджета & бюджета субъекта РФ \\
\hline $2019 *$ & 138760661 & 114238007 & 24522654 \\
\hline 2018 & 116242412 & 92227191 & 24015221 \\
\hline 2017 & 173550936 & 143893325 & 29657611 \\
\hline 2016 & 201670882 & 155306102 & 56364780 \\
\hline 2015 & 220106199 & 167849714 & 52256485 \\
\hline
\end{tabular}

По состоянию на 31 октября 2019 г. по данным Министерства сельского хозяйства (Информационный справочник о мерах и направлениях государственной поддержки агропромышленного комплекса Российской Федерации [Электронный ресурс]: - URL:http://www.gp.specagro.ru/ region/rf/31/ 10/2019).

С учетом ежегодной инфляции (в соответствии с законом о федеральном бюджете в 2019 г. - 4,3 \%) реальная консолидированная господдержка в фактических цифрах сложилась еще меньше.

Кроме снижения консолидированных объемов государственной поддержки относительно 2015 г., к негативным моментам государственного субсидирования следует отнести уже ставшие традиционными мно- 


\section{Социально-экономический и әуманитарный журнал Красноярского ГАУ. 2020. №1}

гократные уточнения и изменения. В 2017 г. размеры господдержки корректировались рекордные 43 раза, в 2018 - 31 раз, в текущем году уже 34 раза и, видимо, рекорд корректировок будет побит в худших традициях внесения изменений в бюджет, образно говоря, - «за пять минут до нового года». Еще одним отрицательным обстоятельством субсидирования отечественного АПК являются большие объемы исправлений объемов финансирования именно в конце финансового года. Например, в декабре 2017 г. господдержка была увеличена на 20 944,4 млн руб., т. е. на 15 \% от годового финансирования. Это косвенно подтверждает несовершенстве механизма субсидирования.

Вместе с тем, несмотря на снижение господдержки АПК, нельзя считать это единственным ограничением для развития сельского хозяйства. Прошлый год еще раз показал, что отрасль серьезно зависит от агрометеорологических условий, импортных семян, племенного материала и медленного внедрения новых технологий. Кстати, поддержка технической и технологической модернизации, а также инновационное развитие сельского хозяйства, финансировались только в 2015 г. в части субсидирования доли прямых затрат на создание и модернизацию объектов АПК в размере 1,6 млрд руб.

Независимо от непогоды в ряде регионов в 2018- 2019 гг. аграрии пятый год подряд сохраняют лидерство на мировом рынке пшеницы. Этому способствует ежегодный сбор урожая с 2013 г. свыше 100 млн т. По данным ФТС, Россия с начала текущего сельскохозяйственного года (с 1 июля по 31 октября 2019 г., т. е. только за 4 месяца сельхозгода) экспортировала 17,5 млн т зерновых культур. За прошлый аграрный год (с 1 июля 2018 г. по 30 июня 2019 г.) экспорт российского зерна составил 43,3 млн т (для сравнения за этот же период США экспортировали 36,5 млн т зерна). Таким образом, Россия по итогам минувшего сельхозгода сохранила первое место в мире по поставкам пшеницы, обогнав как США, так и страны Евросоюза [4].

Кроме того, указом президента «О национальных целях и стратегических задачах развития Российской Федерации на период до 2024 года» перед отраслью ставятся новые цели обеспечения объема экспорта несырьевых неэнергетических товаров в размере $\$ 250$ млрд к 2024 г., в том числе за счет роста экспорта пшеницы до 45 млн т.

Безусловно, касательно экспортных ориентиров главным диктатором этого рынка будет именно импортер, а не наши благие пожелания. Хотя это, впрочем, не снимает ответственности государства в целом, правительства в частности. В этом отношении интересна современная ситуация с экспортом муки. Здесь следует напомнить, что экспорт муки предпочтительнее экспорта зерна. Не углубляясь в особенности зернового рынка, на его поверхности очевидны противоречия экономического 
взаимодействия и политической позиции. Так, например, КНР большую часть муки закупает на Украине, а не в России [2]. Более того, в последние годы Украина без господдержки стабильно расширяет географию и объемы экспорта муки [8]. Он уже вдвое превышает российский. Даже разбомбленная и окруженная санкциями Сирия закупает в России не муку, а зерно. В этом же ряду находится и подписание МСХ РФ меморандума с Ираном о расширении производства муки из российской пшеницы, что сужает наш потенциальный экспорт муки [7].

Однако ситуация с зерновым, а также масличным экспортом является в какой-то степени исключением из правил.

Возвращаясь к вопросу необходимости наращивания объемов сельскохозяйственного производства, следует иметь в виду, во-первых, возможность и уже имеющийся кризис относительного перепроизводства по отдельным позициям; во-вторых, изъяны существующей аграрной политики, не стимулирующие интенсивное технологическое развитие АПК.

Об отсутствии финансирования программы поддержки технической и технологической модернизации, а также инновационного развития сельского хозяйства в Госпрограмме было уже упомянуто выше. Но это не единственный недостаток программы восстановления сельского хозяйства России.

Еще одним сомнительным инструментом сельхозполитики стало активное использование логики отчетности - «импортозамещение любой ценой». Имеется в виду действие межотраслевых и отраслевых комиссий по импортозамещению, официальных статистических, учетных методологий по расчету доли импорта, а также налоговое стимулирование его замещения [6].

Перечисленные средства актуальны хотя бы для мониторинга ситуации, но для обеспечения наступательного протекционизма этого недостаточно. Тем более, если эти показатели основаны на принципах наращивания валового производства без учета требований снижения издержек и повышения конкурентоспособности.

Нельзя оставить без внимания сопоставление размеров субсидиарной господдержки в разрезе федеральных округов Российской Федерации (табл. 2). Как следует из приведенных данных, расхождение в объемах государственного консолидированного субсидирования АПК СевероЗападного и Южного федерального округов достигает двойной кратности. При всей размерной, географической, структурной, климатической, бюджетной несопоставимости остаются сомнения в привязке господдержки к унифицированным целевым показателям для всех федеральных округов. 


\section{Социально-экономический и әуманитарный журнал Красноярского ГАУ. 2020. №1}

Таблица 2

Объемы государственной поддержки АПК РФ в 2018 г. [3]

\begin{tabular}{|c|c|c|c|}
\hline \multirow{3}{*}{ Субъект РФ } & \multicolumn{3}{|c|}{ Предусмотрено всего, тыс. руб. } \\
\hline & \multirow[b]{2}{*}{ Всего } & \multicolumn{2}{|c|}{ В т. ч. за счет средств } \\
\hline & & $\begin{array}{c}\text { федерального } \\
\text { бюджета }\end{array}$ & $\begin{array}{c}\text { бюджета субъекта } \\
\text { РФ }\end{array}$ \\
\hline Архангельская область & 373305 & 335908 & 37397 \\
\hline Вологодскаяобласть & 1027988 & 725124 & 302864 \\
\hline $\begin{array}{l}\text { Калининградская } \\
\text { область }\end{array}$ & 1482407 & 1124081 & 358326 \\
\hline Карелия республика & 195499 & 165646 & 29854 \\
\hline Коми республика & 238675 & 167072 & 71603 \\
\hline Ленинградская область & 1967757 & 964201 & 1003556 \\
\hline Мурманская область & 58071 & 41231 & 16841 \\
\hline $\begin{array}{l}\text { Ненецкий } \\
\text { автономный округ }\end{array}$ & 59216 & 36714 & 22502 \\
\hline Новгородская область & 476900 & 323442 & 153458 \\
\hline Псковская область & 1090140 & 1013830 & 76310 \\
\hline Санкт-Петербург & 60684 & 22453 & 38231 \\
\hline $\begin{array}{l}\text { Итого по Северо- } \\
\text { Западному ФО }\end{array}$ & 7030642 & 4919702 & 2110942 \\
\hline Южный ФО & 14067688 & 11863539 & 2204151 \\
\hline
\end{tabular}

В отсутствии прозрачности расчета объемов финансирования подпрограмм вызывает недоумение отсутствие дифференцированных целевых индикаторов господдержки в разрезе субъектов федерации. Полагаем, что в силу различного биоклиматического аграрного потенциала должны быть разные целевые ориентиры. Например, приграничные территории со сложными климатическими условиями, ресурсными и структурными ограничениями должны получать большую долю финансирования по таким (и некоторым другим) подпрограммам, как:

- поддержка реализации мероприятий по комплексному обустройству населенных пунктов, расположенных в сельской местности, объектами социальной и инженерной инфраструктуры и автомобильными дорогами;

- поддержка реализации мероприятий по улучшению жилищных условий граждан, проживающих в сельской местности;

- поддержка реализации мероприятий по грантовой поддержке местных инициатив граждан, проживающих в сельской местности;

- поощрение и популяризация достижений в сфере развития сельских территорий;

- научно-методическое обеспечение реализации мероприятий федеральной целевой программы. 
Для территорий с благоприятными климатическими условиями, сохраненными производственными мощностями целесообразна бо' льшая поддержка по приоритетному проекту «Экспорт продукции АПК».

В конечном счете ситуация складывается таким образом, что возможность дальнейшего роста упирается в необходимость совершенствования современной аграрной политики, а также инструментов ее реализации в рамках Государственной программы развития сельского хозяйства и регулирования рынков сельскохозяйственной продукции, сырья и продовольствия на 2013-2020 гг. [1]. На данный момент она, как минимум, не стимулирует интенсивное технологическое развитие. При более низкой стоимости труда, земельных ресурсов и производственных показателях реиндустриализированных хозяйств, соответствующих современному мировому уровню, отечественная продукция, за исключением зерновых и масличных культур, не слишком конкурентоспособна без поддержки государства. К этому добавляется странная для нашего агропродовольственного экспорта позиция по перманентным и неэффективным вывозным пошлинам, когда государство, забирая деньги у эффективных секторов, отдает их кому считает нужным, не утруждая себя представлением обоснованной позиции и результативности своих решений, снижая возможность инвестиций и перехода на новые технологии.

Выводы. Анализ государственной поддержки АПК по 4 программам и 12 подпрограммам показал ряд отрицательных моментов: снижение абсолютных объемов; нестабильность программ; частые корректировки объемов субсидирования в течение финансового года; унифицированность программ и отсутствие дифференцированных целевых индикаторов господдержки в разрезе субъектов федерации; отсутствие увязки экономического продвижения экспортных возможностей АПК и политической позиции; перманентные и неэффективные вывозные пошлины.

В конечном счете ситуация складывается таким образом, что возможность дальнейшего роста упирается в необходимость совершенствования современной аграрной политики, а также инструменты ее реализации в рамках Государственной программы развития сельского хозяйства и регулирования рынков сельскохозяйственной продукции, сырья и продовольствия на 2013-2020 гг. [1].

Исходя из проведенного анализа, для формирования благоприятного климата экспортной экспансии необходимо до 2020 г. решить ряд задач, в том числе:

- закрепить в Доктрине продовольственной безопасности положения по развитию агропродовольственного экспорта, признав его основным драйвером развития отрасли;

- отказаться от идеологии сплошного импортозамещения - не важно, если экспорт приведет к росту импорта аналогичной по качеству продукции и мы сможем продать свои товары дороже, а купить аналогичные дешевле; 


\section{Социально-экономический и әуманитарный журнал Красноярского ГАУ. 2020. №1}

- переформатировать аграрную политику с роста валового производства на задачи повышения конкурентоспособности и сконцентрировать бюджетную поддержку на ограниченном круге направлений;

- полностью отказаться от любых таможенно-тарифных мер по ограничению экспорта (если реально возникнет и будет публично доказана угроза национальной продовольственной безопасности, то экспорт должен быть просто запрещен на определенное время);

- отказаться от любых таможенных ограничений на ввоз оборудования для пищевой и перерабатывающей промышленности, если при реализации проекта будет обеспечено производство экспортноориентированной продукции;

- ввести норму об оказании гуманитарной помощи и предоставлении государственных гарантий иностранным государствам на закупку исключительно переработанной сельскохозяйственной продукции;

- установить оценку деятельности надзорных органов, торгпредств и других по критерию расширения рынков сбыта для российской агропродовольственной продукции;

- обеспечить расширение поставок продовольственных товаров поэтапно, не допуская дискриминационных мер по экспорту сырья для их производства.

\section{Литература}

1. О Государственной программе развития сельского хозяйства и регулирования рынков сельскохозяйственной продукции, сырья и продовольствия на 2013-2020 годы: постановление Правительства РФ от 14.07.2012 № 717 (первая ред., ред. от 06.09.2018) // URL: www.consultant.ru.

2. Лидером в экспорте муки в Китай стала Украина: кто и кому так успешно поставляет муку? // Chinalogist. 2018. URL: https:/ / chinalogist.ru (дата обращения: 20.06.2019).

3. Справочник о мерах и направлениях государственной поддержки агропромышленного комплекса Российской Федерации / Мин-во с.-х. хозяйства Российской Федерации // URL: http:// www.gp.specagro.ru/ region/rf (дата обращения: 20.06.2019).

4. Обзор рынков за 15.11.2019 / Мин-во с.-х. хозяйства Российской Федерации // URL: http://mcx.ru/ministry/departments (дата обращения: 25.11.2019).

5. О Правительственной комиссии по импортозамещению: постановление правительства РФ от 04.08.2015 № 785 // URL: www.consultant.ru.

6. Официальный сайт Таможенного союза ЕврАзЭС. URL: http:/ / www.tsouz.ru/ Docs/ IntAgrmnts/ Pages/S_o_vivozn_posM_3stran i.aspx (дата обращения: 20.06.2019). 
7. Россия и Иран предварительно согласовали меморандум об экспорте пшеницы // РИА Новости. URL: https:// ria.ru/20180306/ 1515867876.html (дата обращения: 20.06.2019).

8. Экспорт муки из Украины. URL: https://latifundist.com/novosti/ 42956-eksport-muki-iz-ukrainy-prodolzhaet-snizhatsya (дата обращения: 20.06.2019).

\section{Literatura}

1. O Gosudarstvennoj programme razvitija sel'skogo hozjajstva i regulirovanija rynkov sel'skohozjajstvennoj produkcii, syr'ja i prodovol'stvija na 2013-2020 gody: postanovlenie Pravitel'stva RF ot 14.07.2012 № 717 (pervaja red., red. ot 06.09.2018) // URL: www.consultant.ru.

2. Liderom $v$ jeksporte muki v Kitaj stala Ukraina: kto i komu tak uspeshno postavljaet muku? // Chinalogist. 2018. URL: https:// chinalogist.ru (data obrashhenija: 20.06.2019).

3. Spravochnik o merah i napravlenijah gosudarstvennoj podderzhki agropromyshlennogo kompleksa Rossijskoj Federacii / Min-vo s.-h. hozjajstva Rossijskoj Federacii // URL: http://www.gp.specagro.ru / region/rf (data obrashhenija: 20.06.2019).

4. Obzor rynkov za 15.11.2019 / Min-vo s.-h. hozjajstva Rossijskoj Federacii // URL: http://mcx.ru/ministry/ departments (data obrashhenija: 25.11.2019).

5. O Pravitel'stvennoj komissii po importozameshheniju: postanovlenie pravitel'stva RF ot 04.08.2015 № 785 // URL: www.consultant.ru.

6. Oficial'nyj sajt Tamozhennogo sojuza EvrAzJeS. URL: http:// www.tsouz.ru/ Docs/IntAgrmnts/ Pages/S_o_vivozn_posM_3stran i.aspx (data obrashhenija: 20.06.2019).

7. Rossija i Iran predvaritel'no soglasovali memorandum ob jeksporte pshenicy // RIA Novosti. URL: https://ria.ru/20180306/ 1515867876.html (data obrashhenija: 20.06.2019).

8. J eksport muki iz Ukrainy. URL: https://latifundist.com/novosti/42956eksport-muki-iz-ukrainy-prodolzhaet-snizhatsya (data obrashhenija: 20.06.2019).

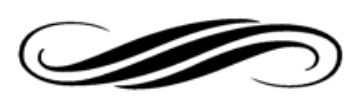

